where over $£$ IO, 000 has been spent on scientific equipment, science is not a compulsory subject ; and, in fact, it is practically impossible to get science teaching on the classical side.

It would be interesting to know how far science is compulsory in the various public schools. I have no doubt there are others, but I only know of two-Eton and Clifton-where it is.

"A Parent."

\section{Discharge of an Electrified Body by Means of the Tesla Spark.}

IT has been shown that a body charged with electricity may be discharged by means of the rays from a Röntgen bulb. I find, also, that an electrified body is rapidly discharged by the influence of a high-frequency spark, such as that produced by the Tesla apparatus. The discharging action was shown in this way. A high-frequency spark was produced between two rather blunt points, one inch apart in air, no bulb being used. A gold-leaf electroscope, placed far away from the influence of the spark, was used to test the electrical condition of the charged bodies-viz. a stick of sealing-wax and a rod of glass. The sealing-wax was rubbed, and the electroscope indicated that it was well charged. It was again rubbed, and then brought to within a foot of the points, and by means of a key in the battery circuit the Tesla coil was thrown into action for an instant. On testing the sealing-wax rod with the electroscope, it was found to be entirely discharged. A similar experiment was next made with a glass rod; the glass rod was entirely discharged by the Tesla spark. From a previous experiment, it was seen that the electrification of the rods was dissimilar. The influence, then, of the high-frequency spark is to discharge electricity of either sign.

Oxford, July 17. FREDERICK J. SMITH.

\section{On the Occurrence of the Pelagic Ova of the Anchovy off Lytham.}

Hitherto no free eggs of this species have been procured in Britain, though Mr. Jackson found ripe:females off Southport in June 1878. Day observes, in the "Brit. Fishes," that the anchovy spawn off our coasts in September and December; though in June specimens have been found with enlarged ova, and so tender that they burst on the slightest interference. On June 26 last, however, Mr. R. L. Ascroft, of Lytham, obtained certain ova in the tow-nets used off Lytham Pier, which he courteously sent for examination in a solution of formalin. These eggs agree in all respects with the descriptions and figures of Hoffman, Wenckebach, and Raffaele, though somewhat larger.

Prof. Hoffman found that the anchovies of the Zuyder Zee were ripe in the months of June and July, and that the eggs were of an oval form, and about $\mathrm{I} \mathrm{mm}$. in length. In July 1886 , Wenckebach captured the same eggs in his tow-nets, and hatched them on the third day. The egg is ovoid, and the yolk reticulated as in other clupeoids, such as the sprat. Raffaele procured the same egg at Naples-from May to September-and also ascertained that hatching took place after two or three days. $\mathrm{He}$ gives the long diameter of the egg as $I \cdot 15$ to $I \cdot 25 \mathrm{~mm}$., and the shorter at 0.5 to $0.55 \mathrm{~mm}$. The larva is provided with a reticulated yolk of little depth, but of great length, extending, indeed, considerably beyond the middle of the body, while the notochord is unicolumnar. In two or three days after hatching the yolk had greatly diminished, the pre-anal fin-membrane was augmented, and the dorsal had likewise passed much further forward. The buccal aperture had also opened, and four branchial arches were visible. The yolk had completely disappeared about the fourth or the fifth day, and pigment occurred in the eye and along the dorsum. The post-pyloric portion of the gut was transversely ridged.

The eggs sent by Mr. Ascroft were, for the most part, advanced; the embryo occupying the long axis of the egg, as usual in such cases, and as shown by Raffaele. The long diameter ranged from $\mathrm{r} \cdot 295$ to $\mathrm{r} \cdot 447 \mathrm{~mm}$., the shorter diameter being almost constant at $0.685 \mathrm{~mm}$.; they are thus larger than those from the Mediterranean and the Zuyder Zee.

Interesting accounts of the occurrence of anchovies off the British shores have been given by Prof. Ewart and Mr. Cunningham, and they would seem to be by no means so rare as at one time supposed. Prof. Ifoffman thought that very rapid growth occurred during the first year of the life of the anchovy, so that those spawned in June and July reached a length of $12 \mathrm{~cm}$. at the end of October, and Dr. Hoek appeared to agree with him. Ehrenbaum, however, asserts that the young anchovies

$$
\text { NO. I396, vOL. 54] }
$$

referred to are in their second year ; and this would be more in harmony with what is known of the herring, the pilchard, and the sprat. This author considered that the anchovy breeds when two years old.

Gatty Marine Laboratory, St. Andrews, July I6.

\section{Information on Scientific Questions.}

Dr. Brown Goode is quoted in Nature of July 16 (p. 252), as saying " he cannot think of any scientific subject regarding which a letter, if addressed to the scientific bureaus in Washington, would not receive a full and practical reply." I infer from this that the replies are prompted by the courtesy of the officers of the various departments, and that the public of the United States possess no right to demand them. If this is so, surely Dr. Brown Goode's scoff at British Government departments is disingenuous, to say the least of it.

But though we have no right to apply for information to Government departments, it must have been the experience of great numbers of people that information may be most readily obtained, and that only very exceptionally does a public officer fail to reply to any reasonable inquiry relating to his own branch of science-or art. I have myself made frequent inquiry of officers of the British Museum, both at Bloomsbury and South Kensington, and in every case (save one) have had courteous and satisfactory replies from those to whom my inquiries were addressed. I have received similar treatment from the Department of Science and Art, from the Society of Antiquaries, from the Board of Trade, from the Agricultural Department, from the Royal Academy, from the School of Mines, and from other bodies which, though in this country they are of a pseudoprivate character, would in the States probably come under some public department.

It may be that the experience of others has been less favourable than mine; but this I find it difficult to believe, and unless Dr. Brown Goode means us to understand that the Washington bureaus may be peremptorily applied to for information, it would be seemly to withdraw the implied charge of discourtesy which he has levelled at our public officers.

I would further point out that in many of our country towns and cities there exist municipal museums, to which local inquiries are first addressed, whence information may be obtained, at, I confess, considerable inconvenience to the curators. I have myself had inquiries on all sorts of questions from agriculturists, medical men, colonists, genealogists, artificers, tradesmen, youthful collectors, and the general public, some of which have taken me two or three hours, and occasionally a microscopic examination of specimens, to solve, and doubtless many other persons could tell of similar experiences. It is quite remarkable how entirely the public have adopted the view that a curator of a museum is a fit and proper person to consult upon any and every subject ; but my experience leads me to think that curators have brought this condition of things upon themselves.

Exeter, July 20.

James Dallas.

\section{Horary Variation of Meteors.}

Dr. DOBERCK, of whose paper an interesting abstract was given on June 25 , informs us that shooting-stars decrease in average magnitude from evening to morning, their duration and length of path decreasing with the magnitude, while the velocity increases as the magnitude diminishes.

This larger evening magnitude is said to be "owing to the fact that the meteorites are heated to incandescence nearer the earth in the evening than in the morning," a fact deserving further explanation.

In the morning we stand on the front of the earth in her orbital motion; the earth then generally meets the meteors with the double velocity of their two motions. In the evening the meteors are overtaking the earth with a slower motion, the difference of their velocities. In the morning, therefore, the meteors enter the atmosphere with double velocity, and are burned up before nearly reaching the earth. In the evening, the slower motion enables them to penetrate further through the atmosphere before becoming incandescent.

So also most aerolites fall in the evening hours, although shooting-stars are most numerous in the morning.

The impalpable air shields the earth from those meteorites whose impact would be dangerous, burning them up by their very velocity, while giving passage to those whose slower motion renders them comparatively harmless.

G. C. Bompas. London, July I8. 